\title{
Prevalence and perceptions of overweight and obesity in Aboriginal and non- Aboriginal young people in custody
}

\section{Leigh Haysom PhD, MMed(ClinEpi), \\ MB BS, Adolescent Health \\ Devon Indig PhD, MPH, BSC, Head of Research, Centre for Health Research in Criminal Justice \\ Elizabeth Moore \\ Senior Research PhD, Centre for Health Research in Criminal Justice \\ Louise L Hardy \\ $\mathrm{PhD}, \mathrm{MPH}$ (Hons) Senior Research Fellow \\ Paul A van den Dolder PhD, MSc MPhysio Director, Ambulatory and Primary Health Care \\ 1 Justice and Forensic Mental Health Network Sydney, NSW. \\ 2 Prevention Research Collaboration, \\ University of Sydney, Sydney, NSW. \\ 3 Illawarra Shoalhaven Local Health District, \\ Wollongong, NSW. \\ leigh.haysom@ justicehealth.nsw.gov.au}

MJA 2013; 199: 266-270 doi: 10.5694/mjal3.10407 ncarcerated youth are one of the most disadvantaged population groups. $^{1,2}$ Compared with their community peers, they have a higher prevalence of risk factors for chronic disease, including alcohol misuse, smoking, mental illness, Aboriginality and lower socioeconomic status. ${ }^{1}$ In 2010, almost a quarter of Australians aged 14-17 years were overweight or obese, and $6 \%$ were obese. ${ }^{3,4}$

A recent review highlighted the disparities in weight, physical activity and nutrition between incarcerated adults and the general population, ${ }^{5}$ but no studies have examined these factors in incarcerated young people. In Australia, New South Wales incarcerates the highest numbers of youths, half of whom are from Aboriginal backgrounds, ${ }^{1,2}$ a 17 times overrepresentation of Aboriginal youth in NSW custody. ${ }^{1}$ Metabolic syndrome and metabolic abnormalities are commonly associated with use of psychotropic medications $^{6}$ and are found in up to a third of young patients treated for their first episode of psychosis. ${ }^{7,8}$ Almost $80 \%$ of incarcerated young people meet criteria for a lifetime mental health disorder (compared with $10 \%$ of 15-19-yearolds in the community), and a fifth are prescribed psychotropic medication. ${ }^{1,9}$ There are also racial, sex and age differences in the self-perception of weight. ${ }^{10}$ In addition, overweight and obese young people, particularly young men, underestimate their weight status. ${ }^{11,12}$ These factors can make weight control among incarcerated young people extremely challenging.

We aimed to examine measured and self-perceived weight status of incarcerated Aboriginal and nonAboriginal young people in NSW, and determine sociodemographic, custodial and other risk factors associated with overweight and obesity at baseline and with selfperceived weight gain over 12 months of follow-up.

Objective: To describe prevalence of and risk factors for overweight, obesity and self-perceived weight gain of Aboriginal and non-Aboriginal Australian young people in custody at baseline and over 12 months of follow-up.

Design, setting and participants: Prospective cohort study of youths in custody in New South Wales, from August 2009, with follow-up at 3, 6 and 12 months.

Main outcome measures: Body mass index at baseline, categorised as overweight or obese using international cut-points; waist-to-height ratio $(\mathrm{WH} \mathrm{tR})$ at baseline, categorised as increased metabolic risk $(\geqslant 0.5)$ or low metabolic risk (<0.5); and self-perceived weight change at follow-up.

Results: At baseline, 452 youths were incarcerated, 361 (79.9\%) consented to participate, and complete anthropometry measurements were taken for 303 (67.0\%). At 3, 6 and 12 months, there were 231 (76.2\%), 158 (52.1\%) and 143 (47.2\%) participants, respectively. Two-hundred and sixty-four (87.1\%) were male, 151 (49.8\%) were Aboriginal, and 145 (47.9\%) had been incarcerated for $<3$ months at baseline. One hundred and forty-five (47.9\%) were overweight or obese and 112 (37.0\%) had a WHtR of $\geqslant 0.5$ at baseline. However, only 72 $(24.1 \%)$ perceived themselves as overweight at baseline, and 154 (71.6\%) perceived a weight increase since incarceration despite improvements in diet and exercise. Longer incarceration time was strongly associated with overweight and obesity in Aboriginal youths at baseline and with self-perceived weight gain in non-Aboriginal youths at follow-up.

Conclusions: Overweight and obesity were highly prevalent but poorly recognised in young people in custody. A longer incarceration time had the strongest association with overweight obesity and self-reported weight gain. From a population health and policy perspective, changes to the liberal food environment and the approach to increasing physical activity in custody are warranted.

\section{Methods}

We conducted a prospective cohort study in eight juvenile justice centres and one high-security juvenile correctional centre, for the 2009 NSW Young People in Custody Health Survey. ${ }^{1}$ Data were collected at baseline and at 3, 6 and 12 months. Informed consent was provided by participants and/or their carers. Ethics approval was obtained from the Justice Health Human Research and Ethics Committee, Juvenile Justice Research Steering Committee, Corrective Services Ethics Committee (Corrective Services NSW) and Aboriginal Health and Medical Research Council Ethics Committee.

All young people in custody between August and October 2009 were invited to participate. Exclusion criteria included insufficient English language skills and being unavailable due to work or court commitments. Participants were followed up in custody (face-to-face or by telephone) or in the community (by telephone).

\section{Anthropometric measurements}

At baseline, height and weight measurements were used to calculate body mass index (BMI), which was used to categorise participants as underweight, healthy weight, overweight or obese. International paediatric definitions of BMI were used for participants aged $\leqslant 18$ years, $^{13}$ and adult definitions for those $>18$ years. ${ }^{14} \mathrm{~A}$ nonextensible steel tape was used to measure waist circumference at the narrowest point between the lower costal border and iliac crest. Waist-toheight ratio (WHtR) was used to categorise participants as low metabolic risk $(<0.5)$ or increased metabolic risk $(\geqslant 0.5){ }^{15,16}$

Self-perceived weight was determined by asking "how do you describe your weight?", "how has your weight changed since being in custody?" and "what are you trying to 
do about your weight?" At each follow-up, participants were asked whether they felt their weight had increased, stayed the same or decreased since the previous occasion on which data were collected.

\section{Risk factors}

Participants completed a baseline questionnaire that was administered face-to-face. Aboriginality was determined by asking "are you of Aboriginal and/or Torres Strait Islander origin?" Postcode of usual residence was used as a proxy measure of socioeconomic status based on the Australian Bureau of Statistics Index of Relative Socio-economic Advantage and Disadvantage (IRSAD) ${ }^{17}$ IRSAD scores were categorised according to quintiles, with first and second quintiles indicating higher disadvantage.

Alcohol consumption in the year before entering custody was measured using the Alcohol Use Disorders Identification Test, with a score $\geqslant 8$ indicating harmful alcohol use. ${ }^{18}$ To identify participants at higher cardiovascular risk, daily smoking was defined as smoking $\geqslant 10$ cigarettes/day in the year before entering custody. Exercise levels were measured by asking "before custody, how often did you usually play sport or do exercises?" and "in the past 2 weeks, how often have you exercised or played sport or games that made you sweat and breathe hard?" Questions on diet before and since incarceration were adapted from standardised national health surveys of children and youth. ${ }^{19,20}$

Lifetime psychological disorders were assessed using the Schedule for Affective Disorders and Schizophrenia for Children - Present and Lifetime Version (KSADS-PL) 2009 Working Draft. ${ }^{21}$ Participants selfreported current psychotropic medication use, out-of-home care and age of first care placement. Time spent incarceration, at each occasion on which data were collected, was calculated through data linkage to the Juvenile Justice NSW and Corrective Services NSW databases.

\section{Analysis}

Participants with complete anthropometric measures were included in the analysis (SPSS version 19; SPSS Inc)

1 Sociodemographic and incarceration characteristics by Aboriginality

Number (percentage)*

\begin{tabular}{ccc}
\hline Total $(n=303)$ & Non-Aboriginal $(n=152)$ & Aboriginal $(n=151)$ \\
\hline $17.1(1.5)$ & $17.4(1.5)$ & $16.7(1.4)^{\dagger}$ \\
$13-21$ & $13-21$ & $13-20$ \\
$224(73.9 \%)$ & $96(63.2 \%)$ & $128(84.8 \%)^{\dagger}$ \\
$264(87.1 \%)$ & $133(87.5 \%)$ & $131(86.8 \%)$ \\
$82(27.7 \%)$ & $27(17.9 \%)$ & $55(37.9 \%)^{\dagger}$ \\
$152(50.2 \%)$ & $74(48.7 \%)$ & $78(51.7 \%)$ \\
$222(77.9 \%)$ & $99(71.7 \%)$ & $123(83.7 \%)^{\dagger}$ \\
$194(76.7 \%)$ & $98(81.0 \%)$ & $96(72.7 \%)$ \\
$210(78.4 \%)$ & $103(75.2 \%)$ & $107(81.7 \%)$ \\
$61(20.7 \%)$ & $27(18.0 \%)$ & $34(23.6 \%)$ \\
& & \\
$145(47.9 \%)$ & $59(38.8 \%)$ & $86(57.0 \%)$ \\
$105(34.7 \%)$ & $56(36.8 \%)$ & $49(32.5 \%)$ \\
$53(17.5 \%)$ & $37(24.3 \%)$ & $16(10.6 \%)^{\dagger}$ \\
$86(28.4 \%)$ & $48(31.6 \%)$ & $38(25.2 \%)$ \\
$124(40.9 \%)$ & $53(34.9 \%)$ & $71(47.0 \%)$ \\
$93(30.7 \%)$ & $51(33.6 \%)$ & $42(27.8 \%)$ \\
\hline
\end{tabular}

* Data are number (percentage) unless otherwise specified. $†$ Significantly different $(P<0.05)$ compared with non-Aboriginal participants. $¥$ Data do not total 303. § Index of Relative Socio-economic Advantage and Disadvantage score in quintile 1 (high disadvantage) or 2 (mid disadvantage).

and data were stratified by Aboriginality. We used $\chi^{2}$ analyses to compare categorical independent variables and $t$ tests for continuous independent variables. Logistic regression was used to determine the association of risk factors for overweight and obesity at baseline and for self-perceived weight gain at follow-up, adjusted for age, sex, IRSAD quintiles and other confounders. $P$ values $<0.05$ were considered significant. "Final follow-up" was defined as the last follow-up for each participant.

\section{Results}

At baseline, 452 youths were incarcerated, 382 (84.5\%) were eligible to participate, $361(79.9 \%)$ consented to participate and 303 (67.0\%) had complete anthropometry measurements taken $(83.9 \%$ of those who consented) (see Appendix; online at mja.com.au). There were no significant differences in age, sex, socioeconomic status or Aboriginality between participants and non-participants. At 3, 6 and 12 months, there were 231 (76.2\%), 158 (52.1\%) and $143(47.2 \%)$ participants, respectively.

Most participants were male (87.1\%), 50.2\% were from areas of higher socioeconomic disadvantage, $49.8 \%$ were Aboriginal and $27.7 \%$ had been placed in out-of-home care before 16 years of age (Box 1). Most had at least one lifetime psychological disorder at baseline (78.4\%) and $20.7 \%$ were taking psychotropic medications at baseline. Most smoked $\geqslant 10$ cigarettes/day (76.7\%) and consumed harmful levels of alcohol $(77.9 \%)$ in the year before entering custody. Compared with non-Aboriginal participants, Aboriginal participants were significantly younger, were more likely to have been in care as a child and to have used harmful levels of alcohol, and were less likely to have been in custody for >12 months at baseline.

Time already spent incarcerated at baseline was $<3$ months for $47.9 \%$ participants, 3-12 months for 34.7\% and $>12$ months for $17.5 \%$. Accumulated incarceration time at final follow-up was <3 months for $28.1 \%$, 312 months for $41.3 \%$ and $>12$ months for $30.7 \%$.

At baseline, $47.9 \%$ of all young people were either overweight or obese, $37.0 \%$ had an increased metabolic risk according to $\mathrm{WHtR}$, and $1.0 \%$ were underweight (Box 2). However, only $24.1 \%$ reported feeling overweight and $20.4 \%$ reported feeling underweight. Compared to non-Aboriginal participants, Aboriginal participants were more likely to report feeling the right weight $(P=0.03)$. Overall, $37.6 \%$ 


\section{Weight characteristics by Aboriginality}

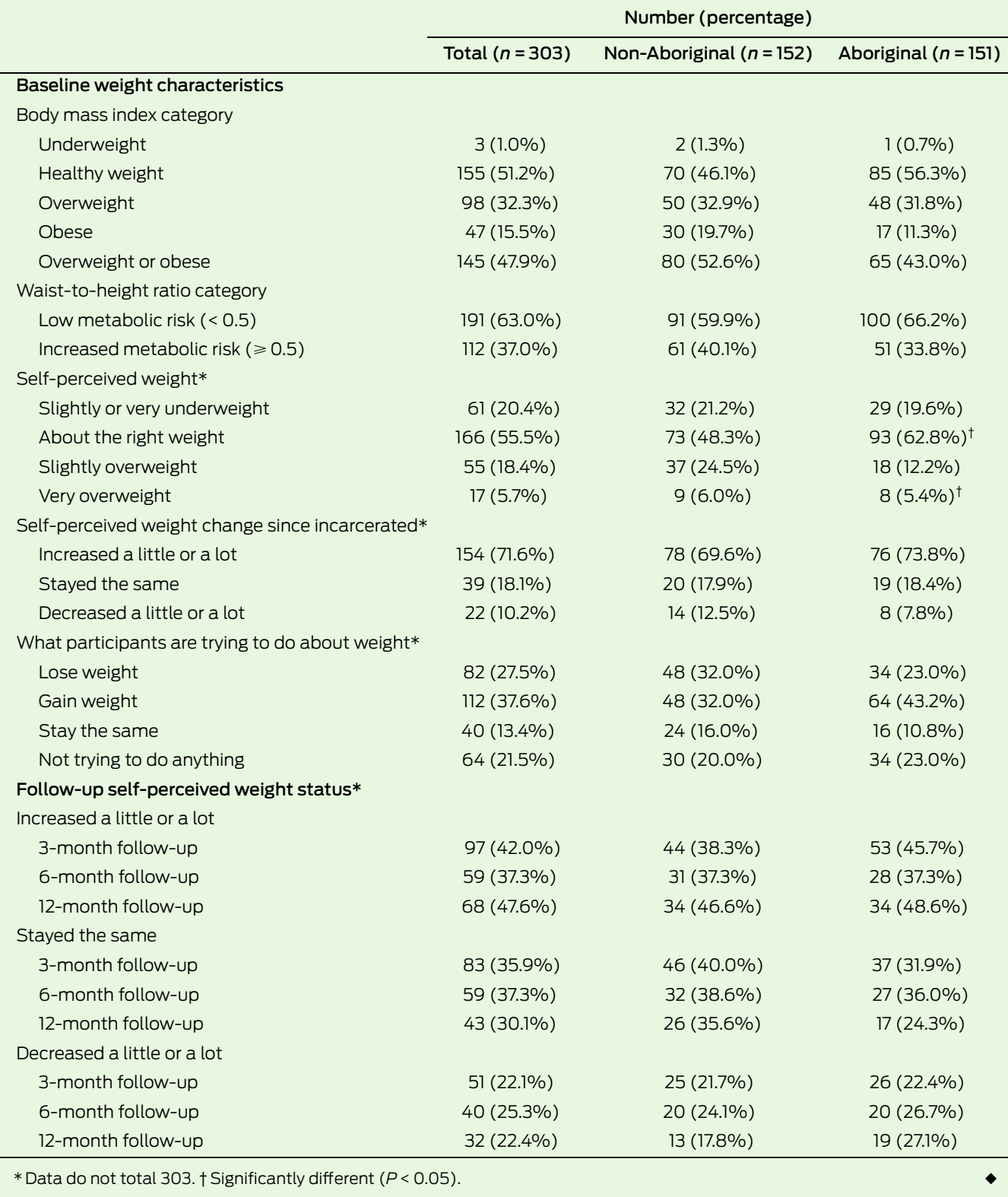

were trying to gain weight at baseline and $27.5 \%$ were trying to lose weight. Since incarceration, $71.6 \%$ perceived a weight increase and $10.2 \%$ perceived a weight decrease. At each follow-up, about a third to a half of young people perceived a weight increase, and about a quarter perceived a weight decrease.

Before incarceration, participants' diets were poor: low intake of fruit and vegetables; high intake of energydense, nutrient-poor foods; and high intake of sugar-sweetened beverages (Box 3). Aboriginal participants were more likely to drink cordial $(P=0.04)$. Daily exercise was reported by $35.1 \%$ of participants before incarceration.
Since incarceration, diets improved significantly, but cordial consumption increased $(P<0.001)$. Daily exercise increased significantly $(P<0.001)$.

Increased metabolic risk, according to WHtR, was strongly associated with overweight or obesity at baseline for the whole group (adjusted odds ratio [AOR], 23.86; $P<0.001)$, with a particularly strong association for Aboriginal participants (AOR, 37.39; $P<0.001$ ) (Box 4). Aboriginal participants trying to lose weight at baseline were six times more likely to be overweight or obese (AOR, 5.79; $P<0.001)$ compared with those not trying to lose weight. Aboriginal participants who had already spent $>12$ months incarcerated at baseline were seven times more likely to be overweight or obese compared with those incarcerated for shorter periods (AOR, 6.92; $P<0.001)$.

Non-Aboriginal participants who had been placed in care before 16 years of age were four times more likely to have a self-perceived weight gain at follow-up compared with those who had not been in care as a child (AOR, 4.21; P=0.04) (Box 5). Non-Aboriginal participants with an accumulated incarceration time of $\geqslant 12$ months at follow-up were three times more likely to perceive weight gain compared with those incarcerated for shorter periods at follow-up (AOR, 2.79; $P=0.04$ ). Young people who felt overweight at baseline had less than half the risk of self-perceived weight gain at follow-up (AOR, 0.44; $P=0.01$.

\section{Discussion}

Incarcerated young people in NSW are at high risk of chronic disease. In our study, almost half were overweight or obese at baseline, and over a third had increased metabolic risk measured by WHtR. A WHtR of $\geqslant 0.5$ was strongly associated with overweight or obesity in Aboriginal participants, confirming this as a useful marker of increased metabolic risk in Aboriginal youths. These are almost twice the rates of overweight, obesity and increased metabolic risk for adolescents in the Australian community, ${ }^{3,22}$ higher than rates seen in young NSW offenders on community orders, ${ }^{23}$ and higher than rates in young men incarcerated in Australian adult prisons (where food is individually rationed), in whom overweight and obesity rates are similar to or lower than community rates. ${ }^{5}$ Three-quarters of young people reported weight gain since being incarcerated, and those who spent a longer time in custody were more likely to report weight gain or be overweight or obese. This suggests that juvenile incarceration is obesogenic, particularly for Aboriginal youth, further increasing their higher background risk of chronic disease. ${ }^{22}$

Participants tended to underestimate their weight status, especially those who were Aboriginal, and many healthy weight and overweight 


\begin{tabular}{|c|c|c|c|c|c|c|}
\hline & \multicolumn{6}{|c|}{ Number (percentage) } \\
\hline & \multicolumn{3}{|c|}{ Before incarceration } & \multicolumn{3}{|c|}{ Since incarcerated (at baseline) } \\
\hline & Total $(n=303)$ & Non-Aboriginal $(n=152)$ & Aboriginal $(n=151)$ & Total $(n=303)$ & Non-Aboriginal $(n=152)$ & Aboriginal $(n=151)$ \\
\hline \multicolumn{7}{|c|}{ Foods eaten $\geqslant 3$ times/week* } \\
\hline Breakfast & $175(58.3 \%)$ & $79(52.3 \%)$ & $96(64.4 \%)^{\dagger}$ & $289(96.3 \%)^{\ddagger}$ & $144(95.4 \%)$ & $145(97.3 \%)$ \\
\hline Fresh fruit & $128(42.7 \%)$ & $60(39.7 \%)$ & $68(45.6 \%)$ & $268(89.3 \%)$ & $139(92.1 \%)$ & $129(86.6 \%)$ \\
\hline Green salad & $121(40.3 \%)$ & $61(40.4 \%)$ & $60(40.3 \%)$ & $193(64.3 \%)$ & $102(67.5 \%)$ & 91 (61.1\%) \\
\hline Fresh vegetables & $168(56.0 \%)$ & $80(53.0 \%)$ & $88(59.1 \%)$ & $229(76.6 \%)^{\ddagger}$ & $116(77.3 \%)$ & $113(75.8 \%)$ \\
\hline Snacks ${ }^{5}$ & $214(71.3 \%)$ & $104(68.9 \%)$ & $110(73.8 \%)$ & $122(40.7 \%)^{\ddagger}$ & $55(36.4 \%)$ & $67(45.0 \%)$ \\
\hline Takeaway food & $226(75.3 \%)$ & $106(70.2 \%)$ & $120(80.5 \%)^{\dagger}$ & $43(14.3 \%)$ & $27(17.9 \%)$ & $16(10.7 \%)$ \\
\hline Milk & $210(70.5 \%)$ & 101 (66.9\%) & $109(74.1 \%)$ & $283(94.3 \%)^{\ddagger}$ & $142(94.0 \%)$ & $141(94.6 \%)$ \\
\hline \multicolumn{7}{|c|}{ Preferred fluids when thirsty* } \\
\hline Water & $156(51.8 \%)$ & $76(50.3 \%)$ & $80(53.3 \%)$ & $227(75.4 \%)^{\ddagger}$ & $115(76.2 \%)$ & $112(74.7 \%)$ \\
\hline Soft drink & $132(43.9 \%)$ & $66(43.7 \%)$ & $66(44.0 \%)$ & $15(5.0 \%)^{\ddagger}$ & $4(2.6 \%)$ & $11(7.3 \%)$ \\
\hline Fruit juice & $52(17.3 \%)$ & $26(17.2 \%)$ & $26(17.3 \%)$ & $32(10.6 \%)^{\ddagger}$ & 15 (9.9\%) & $17(11.3 \%)$ \\
\hline Cordial & $73(24.3 \%)$ & $29(19.2 \%)$ & $44(29.3 \%)^{\dagger}$ & $134(44.5 \%)^{\ddagger}$ & 65 (43.0\%) & 69 (46.0\%) \\
\hline Daily exercise* & 104 (35.1\%) & 46 (30.9\%) & 58 (39.5\%) & $175(58.5 \%)^{\ddagger}$ & $80(53.0 \%)$ & $95(64.2 \%)^{\dagger}$ \\
\hline
\end{tabular}

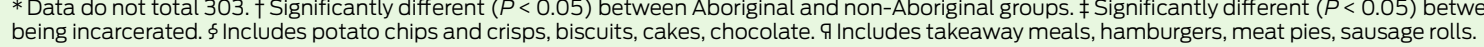

4 Associations with overweight and obesity at baseline by Aboriginality

\begin{tabular}{|c|c|c|c|c|c|c|}
\hline \multirow[b]{2}{*}{ Risk factor } & \multicolumn{2}{|c|}{ Aboriginal $(n=151)$} & \multicolumn{2}{|c|}{ Non-Aboriginal $(n=152)$} & \multicolumn{2}{|c|}{ Total $(n=303)$} \\
\hline & OR $(95 \% \mathrm{Cl})$ & AOR $(95 \% \mathrm{Cl})$ & OR $(95 \% \mathrm{Cl})$ & AOR $(95 \% \mathrm{Cl})$ & OR $(95 \% \mathrm{Cl})$ & AOR $(95 \% \mathrm{Cl})$ \\
\hline Male & $0.45(0.17-1.18)$ & - & $1.11(0.42-2.97)$ & - & $0.71(0.36-1.40)$ & - \\
\hline Aboriginal & na & na & na & na & $0.69(0.44-1.08)$ & - \\
\hline Age $<18$ years & $0.52(0.21-1.29)$ & - & $1.16(0.60-2.25)$ & - & $0.80(0.48-1.33)$ & - \\
\hline Placed in out-of-home care before 16 years of age & $1.05(0.54-2.09)$ & - & $0.50(0.21-1.18)$ & - & $0.72(0.43-1.21)$ & - \\
\hline Daily exercise before incarceration & $0.56(0.28-1.11)$ & - & $0.72(0.36-1.45)$ & - & $0.62(0.38-1.00)$ & - \\
\hline Daily exercise since incarcerated & $0.75(0.38-1.47)$ & - & $0.71(0.37-1.36)$ & - & $0.70(0.44-1.11)$ & - \\
\hline Smoking $\geqslant 10$ cigarettes/day before incarceration & $1.33(0.61-2.90)$ & - & $1.44(0.58-3.60)$ & - & $1.41(0.78-2.55)$ & - \\
\hline Harmful alcohol use before incarceration & $1.10(0.45-2.66)$ & - & $0.64(0.30-1.36)$ & - & $0.75(0.43-1.32)$ & - \\
\hline Lifetime psychological disorder at baseline & $2.05(0.79-5.35)$ & - & $0.76(0.35-1.66)$ & - & $1.09(0.61-1.96)$ & - \\
\hline Psychotropic medication use at baseline & $0.94(0.43-2.05)$ & - & $0.72(0.31-1.67)$ & - & $0.80(0.45-1.41)$ & - \\
\hline $\begin{array}{l}\text { Increased metabolic risk according to WHtR at } \\
\text { baseline }\end{array}$ & $\begin{array}{l}50.52 \\
(14.34-177.94) *\end{array}$ & $\begin{array}{c}37.39 \\
(9.91-141.07) *\end{array}$ & $\begin{array}{c}30.96 \\
(10.22-93.84)^{*}\end{array}$ & $\begin{array}{c}17.28 \\
(5.41-55.21) *\end{array}$ & $\begin{array}{c}39.34 \\
(17.13-90.32) *\end{array}$ & $\begin{array}{c}23.86 \\
(10.03-56.75) *\end{array}$ \\
\hline Self-perceived overweight at baseline & $\begin{array}{c}10.48 \\
(3.39-32.40) *\end{array}$ & $\begin{array}{c}2.08 \\
(0.40-10.74)\end{array}$ & $\begin{array}{c}10.56 \\
(4.10-27.19)^{*}\end{array}$ & $2.88(0.82-10.21)$ & $\begin{array}{c}10.79 \\
(5.24-22.19) *\end{array}$ & $\begin{array}{c}2.54 \\
(0.94-6.83)\end{array}$ \\
\hline Self-perceived weight gain since incarcerated & $\begin{array}{c}0.91 \\
(0.38-2.20)\end{array}$ & - & $\begin{array}{c}0.71 \\
(0.32-1.62)\end{array}$ & - & $\begin{array}{c}0.79 \\
(0.43-1.44)\end{array}$ & - \\
\hline Trying to lose weight at baseline & $\begin{array}{c}13.09 \\
(4.68-36.64) *\end{array}$ & $\begin{array}{c}5.79 \\
(1.37-24.39)^{\dagger}\end{array}$ & $\begin{array}{c}7.88 \\
(3.34-18.59) *\end{array}$ & $\begin{array}{c}1.90 \\
(0.57-6.38)\end{array}$ & $\begin{array}{c}10.04 \\
(5.21-19.35) *\end{array}$ & $\begin{array}{c}3.13 \\
(1.26-7.80)^{\dagger}\end{array}$ \\
\hline Already spent $>12$ months incarcerated at baseline & $\begin{array}{c}4.64 \\
(1.42-15.15) *\end{array}$ & $\begin{array}{c}6.92 \\
(1.66-28.84) *\end{array}$ & $\begin{array}{c}2.31 \\
(1.06-5.05)^{\dagger}\end{array}$ & $\begin{array}{c}1.69 \\
(0.59-4.84)\end{array}$ & $\begin{array}{c}3.07 \\
(1.62-5.81) *\end{array}$ & $\begin{array}{c}2.93 \\
(1.27-6.78)^{\dagger}\end{array}$ \\
\hline
\end{tabular}

youths wanted to gain weight. This desire for weight gain might be a normal expectation in younger men, and there may have been some ambiguity in the interpretation of "gaining weight", but underestimation of weight status in adolescents has been shown in other studies. ${ }^{10-12}$ Despite inaccuracies in self-perceived weight status, Aboriginal young people who reported trying to lose weight at baseline were very likely to be overweight or obese. Those who reported feeling overweight may have been the most receptive to advice on weight control, as these participants were half as likely to report further weight gain at follow-up.

Incarceration is likely to be a proxy for obesity risk factors not measured in this study. There were improvements in diet and exercise for these young people when incarcerated, but, unlike adult prison where each individual receives a daily ration, ${ }^{24}$ juvenile custodial centres supplement breakfast and dinner with liberal access to bread and butter, and allow multiple helpings of meals. Despite drinking more water, participants drank more cordial during incarceration, probably because soft drinks were not readily available. An increase in daily exercise in custody is counterbalanced by daily "lock-downs" to accommodate staff changes and address security concerns, and many youths sleep during this time. Sport is compulsory and incentivised ("no sport, no points"), 


\begin{tabular}{|c|c|c|c|c|c|c|}
\hline \multirow[b]{2}{*}{ Risk factor } & \multicolumn{2}{|c|}{ Aboriginal $(n=130)$} & \multicolumn{2}{|c|}{ Non-Aboriginal $(n=129)$} & \multicolumn{2}{|c|}{ Total $(n=259)$} \\
\hline & OR $(95 \% \mathrm{Cl})$ & AOR $(95 \% \mathrm{Cl})$ & OR $(95 \% \mathrm{Cl})$ & AOR $(95 \% \mathrm{Cl})$ & OR $(95 \% \mathrm{Cl})$ & AOR $(95 \% \mathrm{CI})$ \\
\hline Male & $1.73(0.63-4.71)$ & - & $1.20(0.41-3.54)$ & - & $1.47(0.70-3.05)$ & - \\
\hline Aboriginal origin & na & na & na & na & $0.95(0.58-1.56)$ & - \\
\hline Age $<18$ years & $2.10(0.83-5.34)$ & - & $0.79(0.39-1.62)$ & - & $1.12(0.65-1.93)$ & - \\
\hline Placed in out-of-home care before 16 years of age & $1.43(0.69-2.96)$ & - & $2.96(1.10-7.99)^{\dagger}$ & $4.21(1.33-13.31)^{\dagger}$ & $1.80(1.03-3.16)^{\dagger}$ & $2.22(1.22-4.05) *$ \\
\hline Daily exercise before incarceration & $0.80(0.39-1.65)$ & - & $1.42(0.65-3.09)$ & - & $1.04(0.62-1.76)$ & - \\
\hline Daily exercise since incarcerated & $1.24(0.59-2.60)$ & - & $0.76(0.37-1.53)$ & - & $0.94(0.57-1.56)$ & - \\
\hline Smoking $\geqslant 10$ cigarettes/day before incarceration & $1.00(0.43-2.35)$ & - & $1.01(0.35-2.91)$ & - & $1.03(0.53-1.98)$ & - \\
\hline Harmful alcohol use before incarceration & $1.12(0.44-2.89)$ & - & $0.81(0.36-1.85)$ & - & $0.91(0.50-1.68)$ & - \\
\hline Lifetime psychological disorder at baseline & $0.76(0.29-2.01)$ & - & $1.36(0.58-3.17)$ & - & $1.05(0.56-1.98)$ & - \\
\hline Psychotropic medication use at baseline & $1.18(0.52-2.66)$ & - & $2.71(1.01-7.33)^{\dagger}$ & $3.37(0.83-10.10)$ & $1.66(0.89-3.08)$ & - \\
\hline Overweight or obesity at baseline & $0.98(0.49-1.97)$ & - & $0.61(0.30-1.25)$ & - & $0.78(0.48-1.28)$ & - \\
\hline $\begin{array}{l}\text { Increased metabolic risk according to WHtR at } \\
\text { baseline }\end{array}$ & $1.42(0.67-3.00)$ & - & $0.47(0.23-0.96)^{\dagger}$ & $0.61(0.23-1.64)$ & $0.80(0.48-1.34)$ & - \\
\hline Self-perceived overweight at baseline & $0.50(0.20-1.24)$ & - & $0.40(0.19-0.86)^{\dagger}$ & $0.40(0.14-1.17)$ & $0.46(0.26-0.81)^{\dagger}$ & $0.44(0.24-0.80) *$ \\
\hline Self-perceived weight gain since incarcerated & $1.22(0.47-3.20)$ & - & $1.75(0.72-4.28)$ & - & $1.45(0.76-2.79)$ & - \\
\hline Trying to lose weight at baseline & $1.15(0.51-2.60)$ & - & $0.53(0.25-1.12)$ & - & $0.76(0.44-1.33)$ & - \\
\hline $\begin{array}{l}\text { Spent }>12 \text { months incarcerated at final follow-up } \\
\text { (cumulative) }\end{array}$ & $1.33(0.63-2.83)$ & - & $2.19(1.04-4.58)^{\dagger}$ & $2.79(1.22-6.41)^{\dagger}$ & $1.72(1.02-2.92)^{\dagger}$ & $1.83(1.05-3.20)^{\dagger}$ \\
\hline
\end{tabular}

$* P<0.01 . \dagger P<0.05 . \mathrm{OR}=$ crude odds ratio. AOR = adjusted odds ratio. na = not applicable. WHtR = waist-to-height ratio.

but points can be used to purchase energy-dense, nutrient-poor snacks and beverages.

Low intensity physical activity is a strong appetite stimulant, $^{25}$ so it is likely that incarcerated youths are very hungry at meal times, when they have liberal access to food (in contrast to possibly more restricted access at home). This might explain why those with a history of being in out-of-home care (ie, inconsistent parenting) perceived weight gain at follow-up. These young people have poor track records of self-discipline and impulse control, and some have a tendency to hoard food due to previous scarcity, or because all other privileges have been removed in custody. Despite a lack of association between overweight and obesity and psychological disorders and psychotropic medication use, these relationships need further investigation with prospective measurements of medication type, doses and compliance. Supervision of psychotropic medication use in juvenile custody might lead to better compliance, resulting in weight gain.

This is the first study to document the high prevalence of overweight, obesity and increased metabolic risk in incarcerated young people. Youth incarceration should present opportunities to improve lifestyle and to encourage appropriate weight control measures. From a population health and policy perspective, the current liberal food environment needs to change and approaches to increasing physical activity beyond sport are needed.

Acknowledgements: This study was funded by the Justice and Forensic Mental Health Network and the Centre for Aboriginal Health (NSW Health). We thank staff from Juvenile Justice NSW and Justice Health who provided operational support for the 2009 NSW Young People in Custody Health Survey, and the young people who kindly participated.

Competing interests: No relevant disclosures.

Received 29 Mar 2013, accepted 13 Jun 2013.

1 Indig D, Vecchiato C, Haysom L, et al. 2009 NSW Young People in Custody Health Survey: full report. Sydney: Justice Health and Juvenile Justice, 2011.

22003 NSW Young People in Custody Health Survey: key findings report. Sydney: NSW Department of Juvenile Justice, 2007.

3 Morley B, Sully M, Niven P, Wakefield M. National Secondary Students' Diet and Activity Survey 2008. Melbourne: Cancer Council Victoria, 2010.

4 Hardy L. SPANS 2010: NSW Schools Physical Activity and Nutrition Survey: executive summary. Sydney: University of Sydney, 2011.

5 Herbert K, Plugge E, Foster C, Doll H. Prevalence of risk factors of non-communicable diseases in prison populations worldwide: a systematic review. Lancet 2012; 379: 1975-1982.

6 Garcia G, Logan GE, Gonzalez-Heydrich J. Management of psychotropic medication side effects in children and adolescents. Child Adolesc Psychiatr Clin N Am 2012; 21: 713-738.

7 Ucok A, Gaebel W. Side effects of atypical antipsychotics: a brief overview. World Psychiatry 2008; 7: 58-62.

8 Curtis J, Henry C, Watkins A, et al. Metabolic abnormalities in an early psychosis service: a retrospective, naturalistic cross-sectional study. Early Interv Psychiatry 2011; 5: 108-114.

9 Australian Institute of Health and Welfare. Making progress: the health development and wellbeing of Australia's children and young people. Canberra: Australian Institute of Health and Welfare, 2008. (AlHW Cat. No. PHE 104.)
10 Abbott RA, Lee AJ, Stubbs CO, Davies PS. Accuracy of weight status perception in contemporary Australian children and adolescents. J Paediatr Child Health 2010; 46: 343-348.

11 Khambalia A, Hardy LL, Bauman A. Accuracy of weight perception, life-style behaviours and psychological distress among overweight and obese adolescents. J Paediatr Child Health 2012; 48: 220-227.

12 Chang V, Christakis N. Self perception of weight appropriateness in the United States. Am J Prev Med 2003; 24: 332-339.

13 Cole TJ, Bellizi MC, Flegal KM, Dietz WH. Establishing a standard definition for child overweight and obesity worldwide: international survey. BMJ 2000; 320: 1240-1243.

14 World Health Organization. Physical status: the use and interpretation of anthropometry. Geneva: WHO, 1995.

15 Browning LM, Hsieh SD, Ashwell M. A systematic review of waist-to-height ratio as a screening tool for the prediction of cardiovascular disease and diabetes: 0.5 could be a suitable global boundary value. Nutr Res Rev 2010; 23: 247-269.

16 Garnett SP, Baur LA, Cowell CT. Waist-to-height ratio: a simple option for determining excess central adiposity in young people. Int J Obes (Lond) 2008; 32: 1028-1030.

17 Australian Bureau of Statistics. Census of Population and Housing: SocioEconomic Indexes for Areas (SEIFA). Australia, 2011. Canberra: ABS, 2013. (ABS Cat. No. 2033.0.55.001.)

18 Saunders JB, Aasland OG, Babor TF. Development of the alcohol use disorders identification test (AUDIT): WHO collaborative project on early detection of persons with harmful alcohol consumption. Addiction 1993; 88: 791-804.

19 Zubrick S, Garton AF, Silburn SR. Western Australian Child Health Survey. Perth: Telethon Institute for Child Health Research, 1994.

20 Udry JR. The National Longitudinal Study of Adolescent Health. Chapel Hill: University of North Carolina, 1998.

21 Axelson D, Birmaher B, Zelazny, et al. The Schedule for Affective Disorders and Schizophrenia - Present and Lifetime Version for Children (KSADS-PL) 2009 Working Draft. Advanced Centre for Intervention and Services Research, Western Psychiatric Institute and Clinic, 2009.

22 Australian Institute of Health and Welfare. Australia's health 2012. Canberra: AlHW, 2012. (AlHW Cat. No. AUS 156; Australia's Health Series No. 13.)

23 Kenny DT, Denney-Wilson E, Nelson P, Hardy LL. Eating habits of young offenders on community orders and associations with overweight and obesity. Nutr Diet 2008; 65: 198-204.

24 Indig D, Topp L, Ross B, et al. 2009 NSW Inmate Health Survey: key findings report. Sydney: Justice Health, 2010.

25 Thivel D, Blundell JE, Duche P, Morio B. Acute exercise and subsequent nutritional adaptations. What about obese youths? Sports Med 2012; 42: 607-613. 